\title{
Spatial variation and determinants
} of childhood anemia among children aged 6 to 59 months in Ethiopia: further analysis of Ethiopian demographic and health survey 2016

Tiruneh Ayele Jember ${ }^{1}$, Destaw Fetene Teshome ${ }^{1}$, Lemma Derseh Gezie ${ }^{1}$ and Chilot Desta Agegnehu²*

\begin{abstract}
Background: The magnitude of childhood anemia was increased from time to time. Thus, Even if the Ethiopian government applied tremendous efforts, anemia in children continues as a major public health problem. There is limited evidence on the spatial variation of and determinant factors of childhood anemia at the national level. Therefore, this study aimed to explore spatial distribution and determinants of anemia among children aged 6 to 59 months in Ethiopia.

Method: A stratified two-stage cluster sampling technique was used in Ethiopian Demographic Health Survey 2016 data. In this study 8602 children aged 6-59 months were included. Bernoulli model was used to explore the presence of purely spatial clusters of Anemia in children in age 6-59 months using Sat scan. ArcGIS version 10.3 was used to know the distribution of anemia cases across the country. A mixed-effects Logistic regression model was used to identify determinant factors of anemia.
\end{abstract}

Results: The finding indicates that the spatial distribution of childhood anemia was non-random in the country with Moran's I: $0.65, p<0.001$. The SaT scan analysis identified a total of 180 significant primary clusters located in the Somali and Afar regions ( $L L R=14.47, P$-value $<0.001, R R=1.47$ ). Age of child $12-23$ months $(A O R=0,68,95 \% C l$ : $0.55,0.85), 24-35$ months ( $A O R=0.38,95 \% \mathrm{Cl}: 0.31,0.47$ ), and36-47 months ( $\mathrm{AOR}=0.25,95 \% \mathrm{Cl}, 0.20,0.31$ ), working mother $(A O R=0.87,95 \% \mathrm{Cl}: 0.76,0.99)$, anemic mother $(A O R=1.53,95 \% \mathrm{Cl}, 1.35,1.73)$, had fever in the last 2 weeks $(A O R=1.36,95 \% \mathrm{Cl}: 1.13,1.65)$, moderate stunting $(A O R=1.31,95 \% \mathrm{Cl}: 1.13,1.50)$, Severely stunting $(\mathrm{AOR}=1.82,95 \% \mathrm{Cl}$ : $1.54,2.16)$, religion, wealth index, and number of under-five children in the household were statistically significant associated with childhood anemia.

Conclusion: Spatial variation of childhood anemia across the country was non-random. Age of the child, wealth index, stunting, religion, number of under-five children in the household, fever in the last 2 weeks, anemic mother, and working status of the mother were determinants of childhood anemia. Therefore, interventions should be a

${ }^{*}$ Correspondence: chilotdesta@gmail.com

2 School of Nursing, College of Medicine and Health Sciences

and Comprehensive specialized hospital, University of Gondar, Gondar,

Ethiopia

Full list of author information is available at the end of the article

(C) The Author(s) 2021. Open Access This article is licensed under a Creative Commons Attribution 4.0 International License, which permits use, sharing, adaptation, distribution and reproduction in any medium or format, as long as you give appropriate credit to the original author(s) and the source, provide a link to the Creative Commons licence, and indicate if changes were made. The images or other third party material in this article are included in the article's Creative Commons licence, unless indicated otherwise in a credit line to the material. If material is not included in the article's Creative Commons licence and your intended use is not permitted by statutory regulation or exceeds the permitted use, you will need to obtain permission directly from the copyright holder. To view a copy of this licence, visit http://creativecommons.org/licenses/by/4.0/. The Creative Commons Public Domain Dedication waiver (http://creativeco mmons.org/publicdomain/zero/1.0/) applies to the data made available in this article, unless otherwise stated in a credit line to the data. 
priority concern for high-risk (hot spot) areas regarding allocation of resources and improved access to health facilities, and to reduce the consequence of anemia among the generation policymakers and concerned bodies should be implemented these specific determinant factors.

Keywords: Childhood, Anemia, Spatial, Distribution

\section{Background}

Anemia is a disease that is characterized by a decreased number of red blood cells or hemoglobin levels that result in the insufficient oxygen-carrying capacity of blood to meet the cellular metabolic demand of the body [1]. Iron deficiency is the major cause of anemia and there are also other causes of anemia like, nutritional deficiency, acute and chronic inflammations that affect the synthesis of hemoglobin and production $[1,2]$.

Globally, anemia affects more than $27 \%$ of the world's population which is nearly 1.93 billion. However, there is a high burden of anemia cases in low and middle-income countries which is more than 89\% [3]. Among the global burden of anemia two-third of under-five/ preschool children in Africa and southeast Asia were anemic [4]. On the other hand, according to World Health Organization (WHO) 2017 report, the global prevalence of anemia in under-five children was $41.7 \%$ whereas in the Africa region was 59\% [5]. In sub-Saharan Africa including Ethiopia, the national prevalence of anemia among under five or preschool children was above 40\% [6-8]. For example, in Ethiopia, the prevalence of anemia was persistently increased among 6-59months of children from $44 \%$ in 2011 to $56 \%$ in 2016 within 5 years $[6,7]$.

World Health Organization defined as anemia is a major public health problem when prevalence is above $40 \%$ and Therefore, anemia is a worldwide public health problem that affects both developing and developed countries [4]. It increased mortality and morbidity of human health as well as poor social and economic development [4]. It occurs in all population groups of a human beings. However, children and pregnant women were the more risk age groups for anemia. The result of anemia in children is very severe and complicated like increasing child mortality, impaired cognitive and physical development [2, 4]. Previous various factors were associated with childhood anemia. For example, household wealth index [9-13], Family size [14-16], giving more diversified diet $[12,17,18]$, stunting $[7-10,12$, $14,19]$, malaria infection $[10,11,20]$, anemic mothers $[13,16,19]$ history of diarrhea $[12,21]$, and history of fever $[11,13,18]$ were determinant factors of childhood anemia.

Even though the Ethiopian government and different partners applied tremendous efforts to control the disease, anemia in under 5 years of children continues as a major public health problem [18]. As you know still anemia is a high burden of disease among under-five children and it varies from country to country, region to region. Identifying geographical variations of anemia among children is very important to prioritize and design targeted prevention and intervention programs to reduce the burden of anemia among children at the national level. Therefore, understanding the spatial variation and determinants of anemia among this group of children is important to design effective interventions and to manage program resources fairly.

Identifying and handling factors of childhood anemia is very important to reduce the prevalence of childhood anemia and allocate resources fairy and give more emphasis for regions that had a high distribution of childhood anemia for a better outcome. Thus, this study is designed to assess spatial distribution and determinants of anemia among children aged 6 to 59 months in Ethiopia. The conceptual frame work is described in detail (Fig. 1).

\section{Method}

\section{Study area and data source}

The Ethiopian Demographic and Health Survey (EDHS) is a community-based cross-sectional study conducted from 18 January to 27 June 2016. The study was conducted in Ethiopia $\left(3^{\circ}-14^{\circ} \mathrm{N}\right.$ and $\left.33^{\circ}-48^{\circ} \mathrm{E}\right)$, situated at the eastern horn of Africa (Fig. 2). The country covers 1.1 million square kilometers and has a great geographical diversity, which ranges $4550 \mathrm{~m}$ above sea level down to the Afar depression to $110 \mathrm{~m}$ below sea level [26]. There are nine regional states and two city administrations subdivided into 68 zones, 817 districts, and 16,253 kebeles (lowest local administrative units of the country in the administrative structure of the country) [7]. The source of the data for this study was the Ethiopian Demographic and Health Survey (EDHS) $2016(N=7794)$ and used to assess the spatial variation and determinants of childhood anemia among children age 6-59months in Ethiopia.

\section{Sample size determination and sampling procedure}

EDHS used a two-stage cluster sampling technique. Since Ethiopia has 9 regional states and 2 administrative cities. Administratively, regions in Ethiopia are divided 


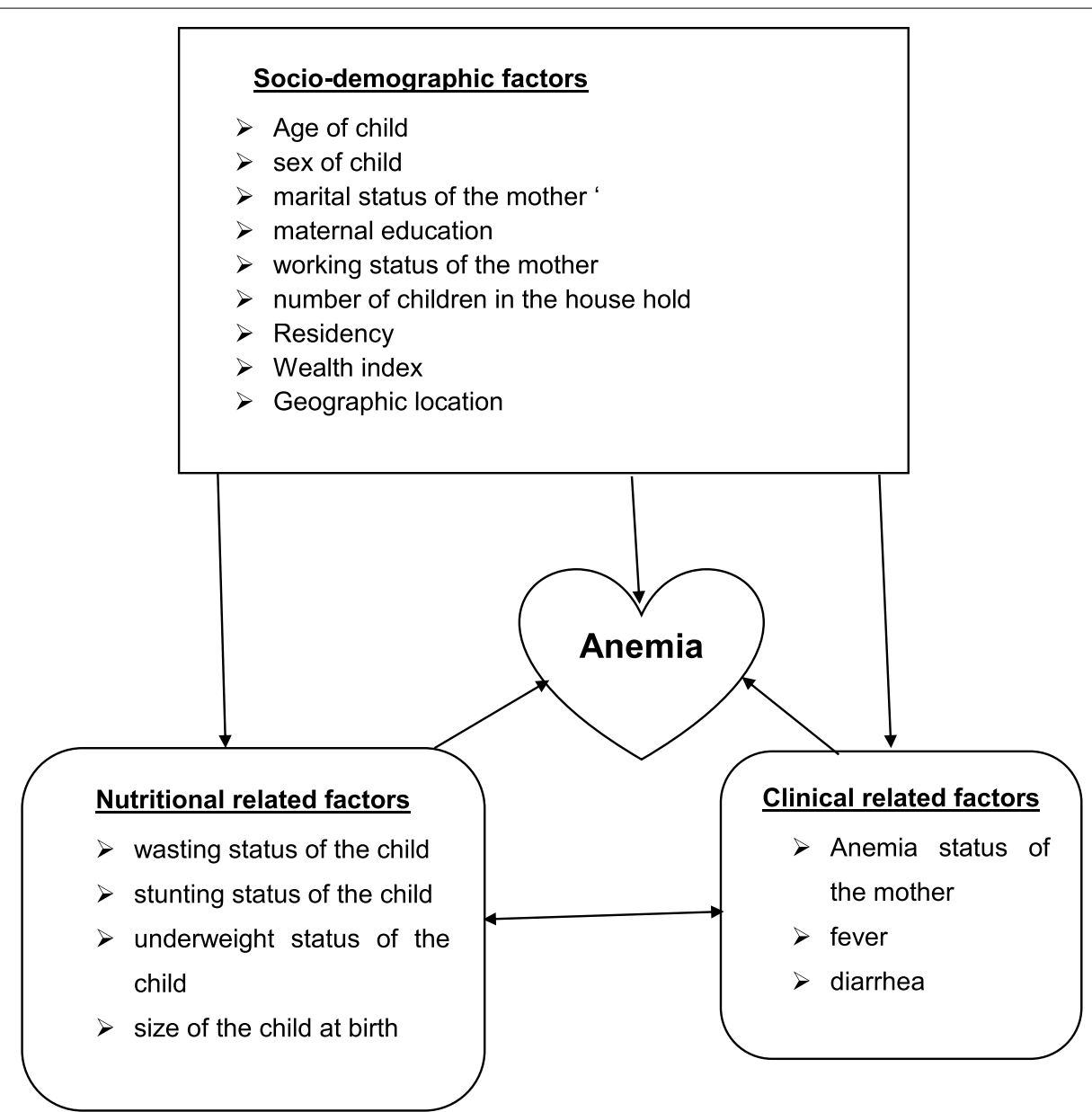

Fig. 1 Conceptual framework of the study adopted from kinds of literature [9-25]

into zones, and zones, into administrative units called woreda. Each woreda is further subdivided into the lowest administrative unit, called kebeles. During the 2007 census, each kebele was subdivided into census enumeration areas (EA), which were convenient for the implementation of the census [7].

A stratified two-stage cluster sampling procedure was employed where EA is the sampling unit for the first stage and households for the second stage. In 2016 EDHS, a total of 645 EAs (202 in urban areas and 443 in rural areas) were selected with probability proportional to EA size (based on the 2007 housing and population census) and with independent selection in each sampling stratum. Of this 18,008 households were included. A total of 8602 children were interviewed. But in the present study, a total of 7794 children the age of 6-59months were included in the analysis. The source population was all births from reproductive-age women within 5 years before the survey in Ethiopia and all births from reproductive-age women in the selected enumeration areas within 5 years before the survey were the study population. Birth's from reproductive age women within 5 years before the survey within enumeration areas with missed global positioning system (GPS) cells were excluded for spatial analysis.

\section{Outcome variable}

The outcome variable for this study was anemia, which was dichotomized as anemic and not anemic. Individuals are considered to be not anemic was defined as Adjusted concentration of blood hemoglobin greater than or equal to $11 \mathrm{mg} / \mathrm{dl}$ and those individuals with less than $11 \mathrm{mg}$ / $\mathrm{dl}$ were anemic [1]. Anemia status was determined based on hemoglobin concentration in blood adjusted to the altitude.

\section{Independent variables}

The independent variables were classified as: sociodemographic factors, nutritional factors, clinical factors, and service-related factors. 


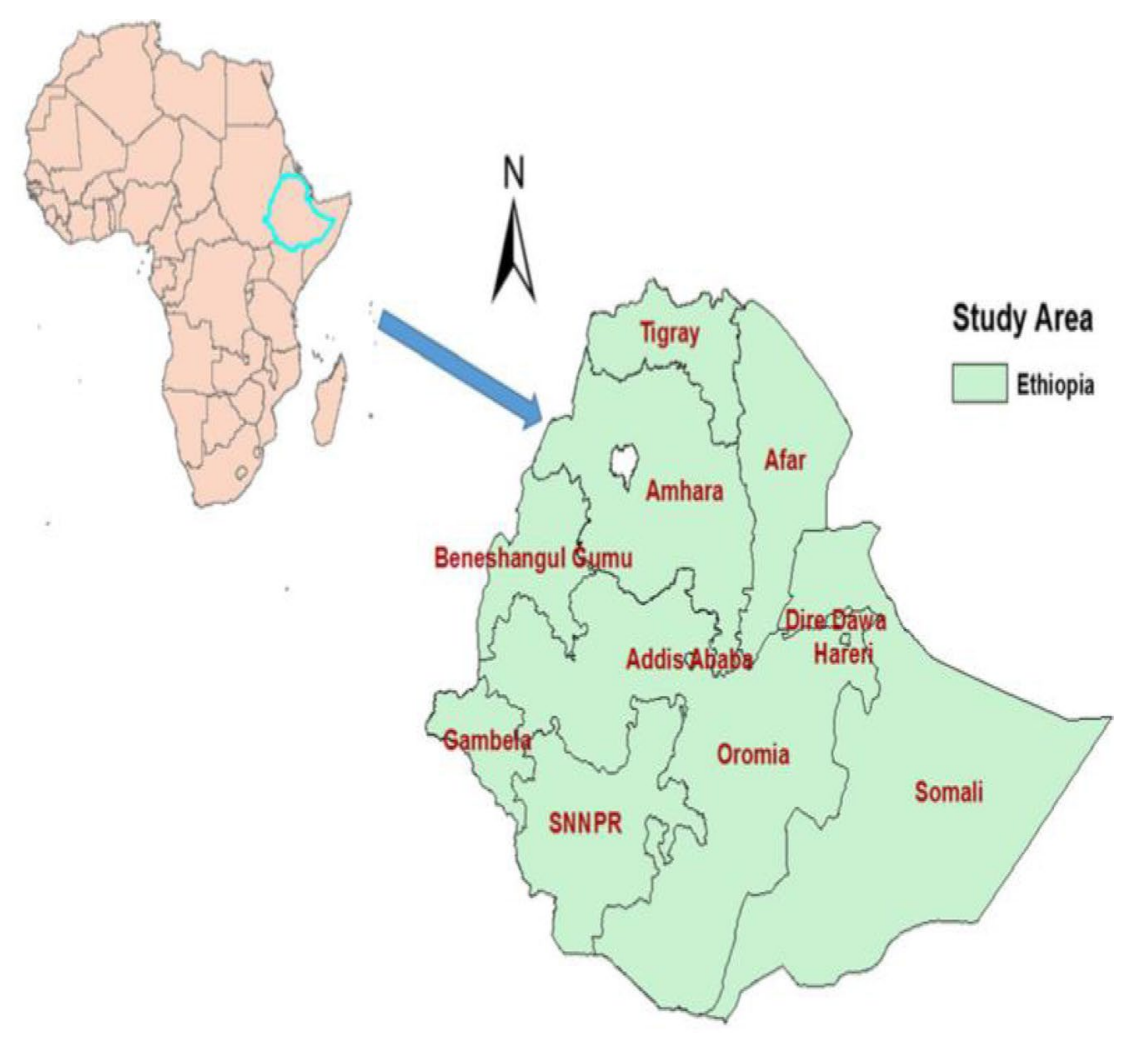

0 112.5225 450 Kilometers

Shape file: central statistics agency, 2016

Fig. 2 Map of Study Area

The socio-demographic factors were the sex of a child, age of child, residence, educational status of the mother, maternal age, husband's educational status, the religion of mother, wealth index, working status of the mother, and a number of children in the household. The nutritional factors were stunting status of a child, wasting status of child, and size of child at birth. The clinical factors were also maternal anemic status, diarrhea in a child in the last 2 weeks, fever in a child in the last 2 weeks, and cough in a child in the last 2 weeks and the service-related factors were taking of vitamin A in the last 6 months, taking of iron pills or sprinkles or syrup and taking of drugs for intestinal parasites in the last 6 months.

\section{Data management and statistical analysis}

Descriptive and summary statistics were done using STATA version 14 after extraction and edition of data from EDHS 2016 child data set. Since EDHS data had hierarchical and clustering nature, the assumption of independence among observations was violated. This implies a need to consider the between-cluster variability by using advanced models. The goodness of fit test was checked using Intraclass correlation (ICC) and deviance [27]. So logistic regression (non-anemic child $=0$, anemic child $=1$ ), and GLMM (generalized linear mixed model) were fitted. Then the GLMM was selected based on the result of Akaikie Information Criteria (AIC) and Bayesian information criteria (BIC). The model with the smallest AIC value was chosen. Variables having a $p$-value up to 0.2 in the bi-variable analysis were selected to fit the model in the multivariable analysis. Finally, a p-value less than 0.05 in the multivariable model of mixed-effects logistic regression was used to select variables that had a statistically significant association with anemia.

\section{Spatial autocorrelation}

ArcGIS version 10.3 was used for Moran's I analysis. The Global Moran's I spatial statistic measures were used to measure spatial autocorrelation by taking the total data set and producing a single output value that ranges from -1 to +1 . Global Moran's I value closes to -1 which indicates dispersed childhood anemia, 
whereas Moran's I value closest to +1 indicted clustered childhood anemia and the Moran's I value is 0 which indicates randomly distributed childhood anemia. Moran's I $(P$-value $<0.05)$ indicates the presence of spatial autocorrelation.

\section{Hot spot analysis (Getis-OrdGi* statistic)}

Getis-OrdGi* statistics were computed to measure how spatial autocorrelation varies over the study location by calculating $\mathrm{GI}^{*}$ statistics for each area. Z-score is computed to determine the statistical significance of clustering, and the $p$-value is computed for the significance [28]. Statistical output with high GI* indicates "hotspot" whereas low GI" means a "cold spot [29-31].

\section{Spatial interpolation}

It is very difficult and expensive in terms of resources and time to collect reliable data in all areas of the country to know the burden of a certain event. Therefore, part of a certain area can be predicted by using observed data using a method called interpolation. The spatial interpolation technique is used to predict childhood anemia in the un-sampled areas in the country based on sampled EAs. There are different deterministic and geostatistical interpolation methods. Among those methods, ordinary Kriging and empirical Bayesian Kriging are considered the best method since it incorporates the spatial autocorrelation and it statistically optimizes the weight [32]. The ordinary Kriging spatial interpolation method was used for this study for predictions of childhood anemia in unobserved areas of Ethiopia.

\section{Disease cluster detection and spatial scan statistical analysis}

Spatial scan statistical analysis was employed to test for the presence of statistically significant spatial hotspots/ clusters of childhood anemia using Kuldorff's SaT Scan version 9.6 software. The spatial scan statistic uses a scanning window that moves across the study area. Children with anemia were taken as cases and without it as controls to fit the Bernoulli model. The numbers of cases in each location had Bernoulli distribution and the model required data for cases, controls, and geographic coordinates. The default maximum spatial cluster size of $<50 \%$ of the population was used, as an upper limit, which allowed both small and large clusters to be detected and ignored clusters that contained more than the maximum limit.

For each potential cluster, a likelihood ratio test statistic and $p$-value were used to determine if the number of observed childhood anemia within the potential cluster was significantly higher than expected or not. The primary and secondary clusters are identified and assigned $p$-values and ranked based on their likelihood ratio test, based on 999 Monte Carlo replications.

\section{Result}

\section{Socio-demographic characteristics}

The EDHS of 2016 includes 8602 children aged 6 to 59 months in the survey. Among these children, $7815(90.8 \%)$ were granted the consent statement for hemoglobin. Of the total of 7815 children whose consent statement is granted, the hemoglobin level was determined for 7794 children which gives a $90.6 \%$ response rate of the study. Their mean age was found to be 32 months ( $S D \pm 0.18$ months). Almost half, $48.6 \%$, of the children were females. The Majority of study participants, $83 \%$, had rural residency. Regarding the educational status of their mothers, two-third (65\%) of mothers had no formal education (Table 1).

\section{Spatial distribution of childhood anemia in Ethiopia}

A total of 622 clusters were considered for spatial analysis of childhood anemia. The red color indicates a high proportion of childhood anemia whereas the green color indicates a low proportion of childhood anemia. A high proportion of childhood anemia occurred in southwest Somali, the eastern and southern part of Oromia, south Afar, Hareri Northern part of Gambella, and Dire Dawa whereas a low proportion of childhood anemia were aggregated in Amhara, Addis Ababa, west of SNNP, and east of Benshangul (Fig. 3).

\section{Spatial autocorrelation}

The analysis of spatial autocorrelation indicated that the spatial distribution of childhood anemia was nonrandom in Ethiopia. The Global Moran's I value 0.14 $(p$-value $<0.0001)$ indicated that there was significant clustering of childhood anemia in the study area (Fig. 4).

Hot and cold spot analysis of childhood anemia in Ethiopia In the Getis OrdGi statistical analysis, significant hotspot areas (high risk of childhood anemia) were aggregated in North and south Eastern part of Somali, Northwest and Sothern part of Afar, Northern part of Gambella, Dire Dawa, and Hareri, while the cold spot areas (low-risk childhood anemia) were found southwest Amhara, Addis Ababa, North West SNNPR and North and South part of Beneshangul Gumuz (Fig. 5).

\section{The spatial interpolation analysis result}

The spatial ordinary kriging interpolation analysis predicted high-risk regions for childhood anemia. 
Table 1 A Socio-demographic characteristic of the children aged 6 to 59 months and their parents in Ethiopia from January 18 to June 27 in $2016(N=7794)$

\begin{tabular}{|c|c|c|c|}
\hline Variable & Categories & Frequency & Percent \\
\hline \multirow[t]{5}{*}{ Age of the child in months } & $6-11$ & 914 & 11.7 \\
\hline & $12-23$ & 1765 & 22.7 \\
\hline & $24-35$ & 1702 & 21.8 \\
\hline & $36-47$ & 1656 & 21.3 \\
\hline & $48-59$ & 1757 & 22.5 \\
\hline \multirow[t]{2}{*}{ Sex of the child } & Male & 4010 & 51.4 \\
\hline & Female & 3784 & 48.6 \\
\hline \multirow[t]{2}{*}{ Residence } & Urban & 1327 & 17.0 \\
\hline & Rural & 6467 & 83.0 \\
\hline \multirow[t]{4}{*}{ Religion of mothers } & Orthodox & 2350 & 30.2 \\
\hline & Protestant & 1417 & 18.2 \\
\hline & Muslim & 3837 & 49.2 \\
\hline & Others & 190 & 2.4 \\
\hline \multirow[t]{4}{*}{ Maternal educational level } & No education & 5084 & 65.2 \\
\hline & Primary & 1981 & 25.4 \\
\hline & Secondary & 486 & 6.3 \\
\hline & Higher & 243 & 3.1 \\
\hline \multirow[t]{4}{*}{ Maternal age in years } & $15-24$ & 1757 & 22.5 \\
\hline & $25-29$ & 2355 & 30.2 \\
\hline & $30-34$ & 1778 & 22.8 \\
\hline & $35-48$ & 1904 & 24.5 \\
\hline \multirow[t]{5}{*}{ Wealth index of child's family } & Poorest & 2854 & 36.6 \\
\hline & Poorer & 1387 & 17.8 \\
\hline & Middle & 1156 & 14.8 \\
\hline & Richer & 983 & 12.6 \\
\hline & Richest & 1414 & 18.2 \\
\hline \multirow[t]{11}{*}{ Region } & Tigray & 828 & 10.6 \\
\hline & Afar & 744 & 9.6 \\
\hline & Amhara & 783 & 10.0 \\
\hline & Oromia & 1220 & 15.7 \\
\hline & Somali & 1019 & 13.0 \\
\hline & Benishangul & 659 & 8.5 \\
\hline & SNNPR & 995 & 12.8 \\
\hline & Gambella & 509 & 6.5 \\
\hline & Harari & 373 & 4.8 \\
\hline & Addis Ababa & 305 & 3.9 \\
\hline & Dire Dawa & 359 & 4.6 \\
\hline
\end{tabular}

Predication of high-risk areas was indicated by red predictions. West and eastern part of Somali, the eastern part of Amhara, South East Tigray, Eastern and Southern afar, Harari, and Dire Dawa regions were predicted as more risky areas compared to other regions. To the opposite of this North West Amhara, Addis Ababa, South West Oromia, and Benshangul Gumuz regions were predicated as having the least risk for anemia (Fig. 6).
Spatial SaT scan analysis of childhood anemia (Bernoulli based model)

A total of 6 clusters with 70 significant enumeration areas were identified and there are two most likely primary clusters and 4 secondary clusters. The primary clusters spatial window encompasses North West of part Oromia, Harari, Dire Dawa, North West Somali, and entire and North West Afar regions. It was centered at $.775278 \mathrm{~N}$, $37.939392 \mathrm{E}) / 0 \mathrm{~km}$ radius and $11.195383 \mathrm{~N}, 39.269363$ E) / $9.21 \mathrm{~km}$, with a relative risk (RR) of 1.67 and LogLikelihood ratio (LLR) of 16.36 and 13.29 , at $p$-value $<0.001$. The RR of 1.67 for clusters spatial window means children within the spatial window had a $67 \%$ increased risk of anemia than children outside the window (Fig. 7) (Table 2).

\section{Factors associated with childhood anemia}

The null model, variance component analysis was performed to decompose the total variance of childhood anemia. The cluster-level variance which shows the total variance of childhood anemia that can be attributed to the context of the community (cluster) in which the child was living was estimated. The applicability of the multi-level mixed-effects logistic regression model in the analysis was justified by the significance of the community-level variance [community variance $=1.24$; standard error $(\mathrm{SE})=0.089 ; P$-value $=0.001]$, indicating the existence of significant differences between communities (clusters) regarding the childhood anemia. This was supported by the ICC value $(\mathrm{ICC}=0.12)$ which revealed that $12 \%$ of the total variance of childhood anemia in Ethiopia can be attributed to the context of the communities. Since it was above the cut of point.

According to mixed-effects logistic regression analysis age of child, religion, wealth index, mother's current working status, maternal anemic status, number of under-five children in the household, fever in the last 2 weeks, and stunting remained statistically significant variables for anemia in children aged 6 to 59 months.

The odds of developing anemia in children whose age was between 12 and 23, 24-35, 36-47 and 48-59 months is lower by $32 \%(\mathrm{AOR}=0.68,95 \% \mathrm{CI}=0.55-0.85), 62 \%$ $(\mathrm{AOR}=0.38,95 \% \mathrm{CI}=0.31-0.47), 75 \% \quad(\mathrm{AOR}=0.25$, $95 \% \mathrm{CI}=0.2-0.31)$ and $84 \%(\mathrm{AOR}=0.16,95 \% \mathrm{CI}=0.13-$ 0.20 ) respectively as compared with those whose age was between 6 and 11 months.

The odds of developing anemia in children having Mus$\lim$ mother is 2.07 times $(\mathrm{AOR}=2.07,95 \% \mathrm{CI}=1.75$ 2.46) that of children having Orthodox mother. Regarding the wealth index, The odds of developing anemia in children with family wealth index of poor, middle, richer and richest is lower by $26 \%$ ( $\mathrm{AOR}=0.74,95 \% \mathrm{CI}=0.63-0.88)$, 


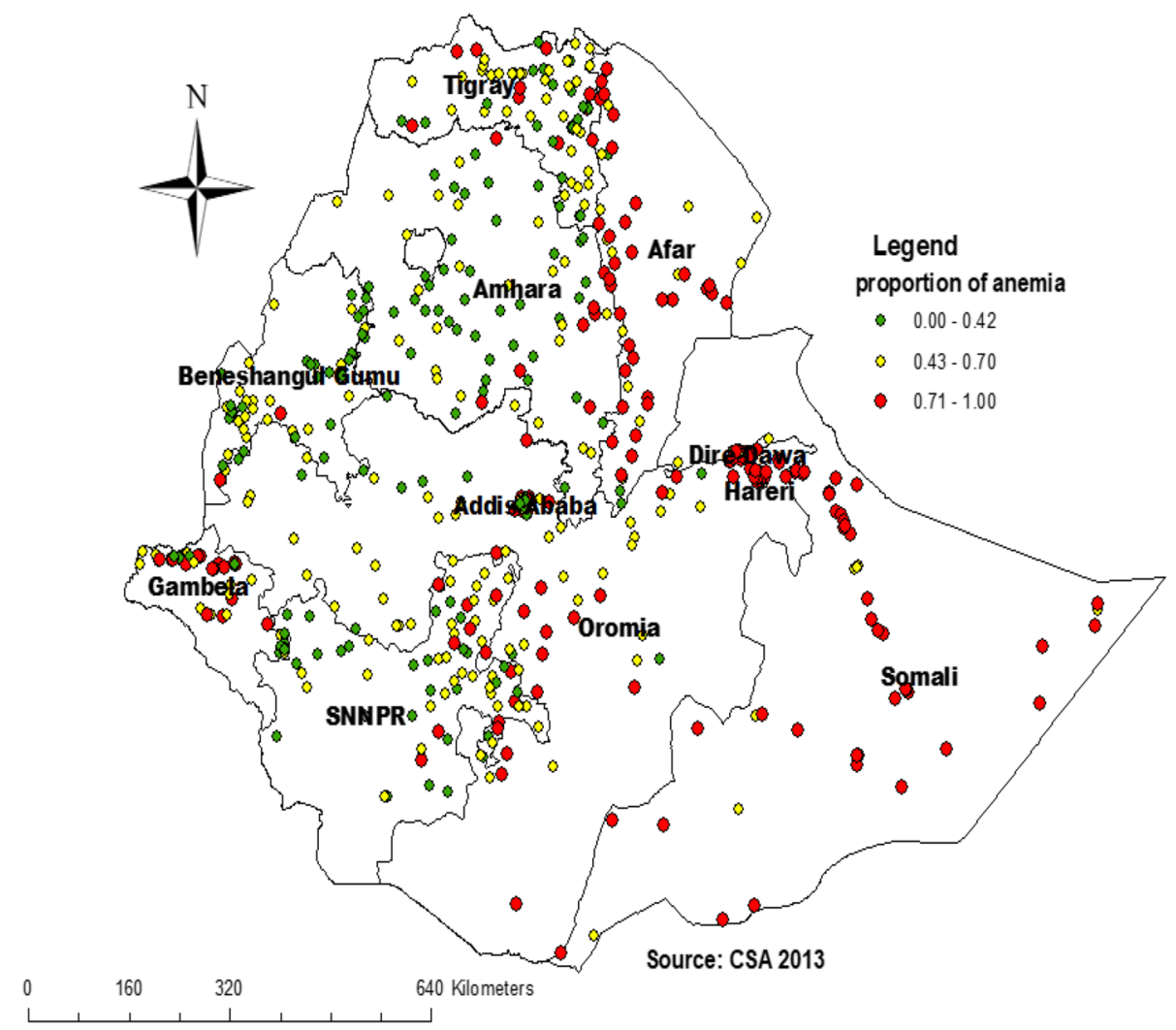

Fig. 3 Spatial distribution of childhood anemia in Ethiopia, 2016

$40 \%(\mathrm{AOR}=0.60,95 \% \mathrm{CI}=0.50-0.72), 35 \%(\mathrm{AOR}=0.65$, $95 \% \mathrm{CI}=0.53-0.79)$ and $43 \%(\mathrm{AOR}=0.57,95 \% \mathrm{CI}=0.43-$ 0.74 ) as compared with those with family wealth index of poorest.

Children whose mother was currently working are lower by $13 \%$ (AOR $=0.87(95 \% \mathrm{CI}=0.76-0.99)$ developing childhood anemia than their counterparts. Regarding maternal anemia status, children whose mother was anemic is 1.53 times $(\mathrm{AOR}=1.53,95 \% \mathrm{CI}=1.35-1.73)$ more likely to develop anemia as compared to children whose mother is free from an anemic.

The odds of developing anemia in children whose household had three or more under-five children is 1.19 times $(\mathrm{AOR}=1.19,95 \% \mathrm{CI}=1.03-1.38)$ that of children whose household had one or two under-five children.

Children who had a fever within the last 2 weeks preceding the interview are 1.36 times $(\mathrm{AOR}=1.36$, $95 \% \mathrm{CI}=1.13-1.65)$ more likely to develop childhood anemia as compared to those who had no fever within the last 2 weeks.

The odds of developing anemia in a child who had moderate and severe stunting is $1.30 \quad(\mathrm{AOR}=1.30$, $95 \% \mathrm{CI}=1.13-1.50)$ and $1.82(\mathrm{AOR}=1.82,95 \% \mathrm{CI}=1.54-$ 2.16) times that of those who had no stunting (Table 3 ).

\section{Discussion}

The purpose of this study is to investigate spatial variation and determinants of childhood anemia aged 6 to 59 months in Ethiopia by using 2016 EDHS data. The spatial variation of childhood anemia was non-random across the country with Global Moran's I 0.65 ( $p$-value $<0.0001)$. This indicated that there was significant clustering of childhood anemia in Ethiopia. The Purely Spatial Sat Scan analysis identified primary and secondary significant clusters of childhood anemia.

Different methods of spatial analysis most consistently demonstrate anemia high risk and low-risk regions. The hotspot areas (high risk of childhood anemia) were aggregated in the North and southeastern part of Somali, North West and Sothern part of Afar, Northern part of Gambella, Dire Dawa, and Hareri. Whereas the most significant clusters were North West of part Oromia, Harari, and Dire Dawa, North West Somali, and entire and North West Afar regions. Regional differences in feeding habits, the distribution of infectious diseases, and the availability and access to use maternal and child health care services could be the most important reasons for the result of regional variability of childhood anemia in our country [33]. Geographic variation is the risk of anemia and 


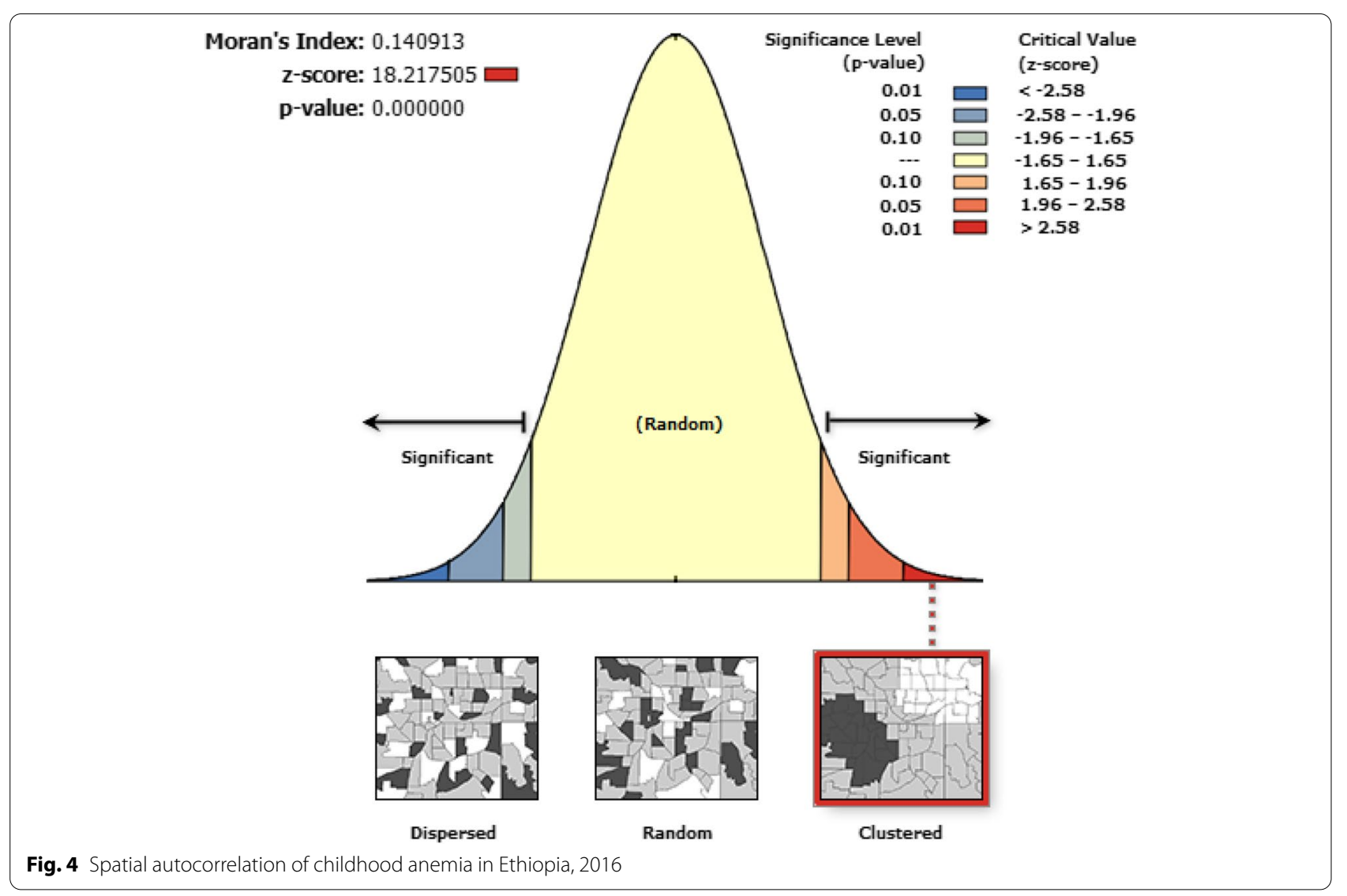

dynamics of the soil content of minerals since the identified high-risk regions were categorized to Eastern and South-Eastern parts of the country. Meaning high-risk regions share similar environmental conditions as evidenced by boundary formation to each other. In addition, epidemiological factors such as fever and stunting which are identified as determinants of anemia in different studies including our studies were more common in some regions. Similarly, the finding from Nigeria showed a distinct North-South divide in the Hemoglobin concentration of the children and that states in the Northern part possess a higher risk of anemia [11]. Furthermore, our finding is also supported by the study conducted in subSaharan Africa which concludes that the distribution of anemia is driven by large-scale environmental factors [8]. These all imply that the dynamics of the mineral content of the soil is the most probable explanation for observed geographical variation in the risk of anemia.

According to mixed-effect logistic regression, age of the child, the religion of mother, wealth index, mother's current working status, maternal anemic status, number of under-five children in the household, fever in the last 2 weeks, and stunting were statistically significant factors childhood anemia in Ethiopia.
Age is one of the most important predictors of childhood anemia. The odds of developing childhood anemia in children whose age was between 12 and 23, 24-35, $36-47$ and $48-59$ months is lower by $32,62,75$, and $84 \%$ respectively as compared with those whose age was between 6 and 11 months. This finding is consistent with several studies around the world [9, 10, 12-17, 19-23]. This is due to a wide gap between high iron demand for fast growth [4] and low iron supply because of inappropriate initiation of complementary feeding $[12,34]$ and the highest depletion of the prenatal iron store starting at 6 months of age [35]. Furthermore, children's age more than 12 months commonly consume a variety of foods that contain iron contents like meat, fish, poultry, and cereals [36]. In addition, different infectious diseases like intestinal helminths are very common in younger children because they might ingest contaminated things into their mouths compared to older ones, particularly children living in an unsanitary environment [37, 38]. All these reasons in turn younger age which is less than 12 months more prone to anemia.

Wealth index was a determinant factor of childhood anemia in Ethiopia The odds of developing anemia in a child with family wealth index of poor, middle, richer, 


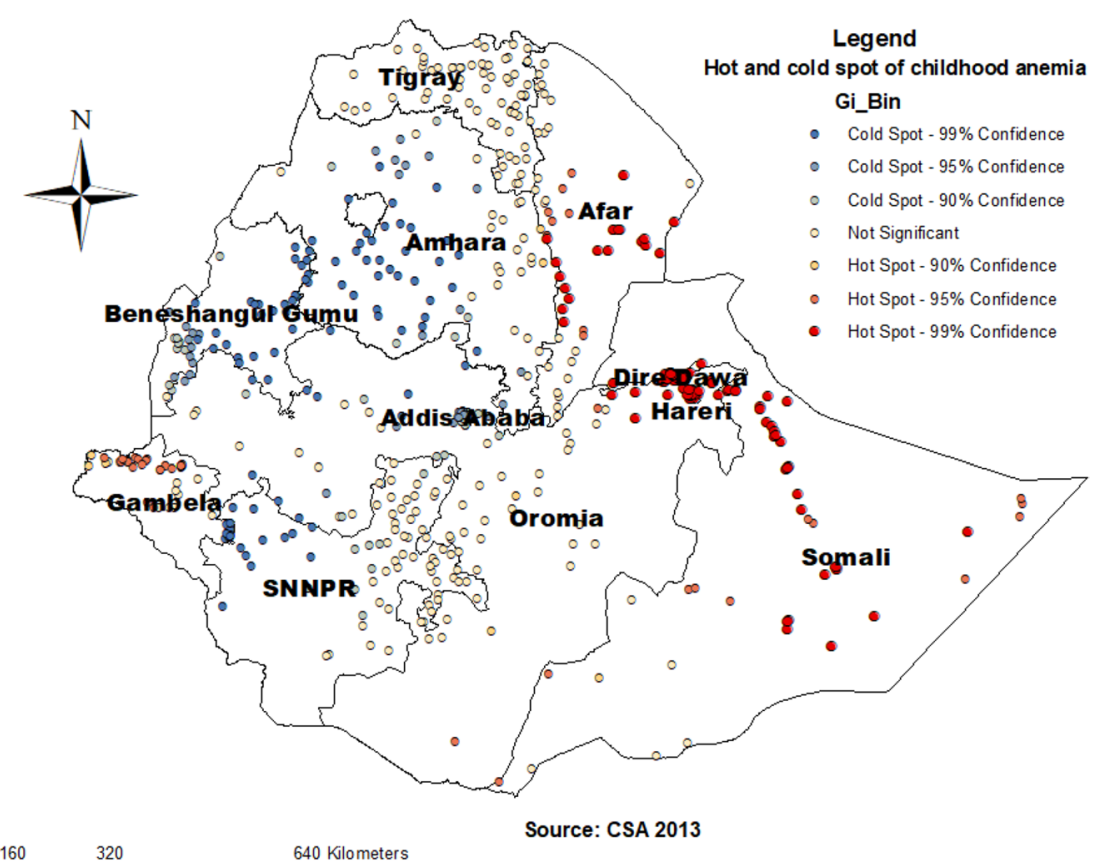

Fig. 5 Hot and cold spot analysis of childhood anemia in Ethiopia, 2016

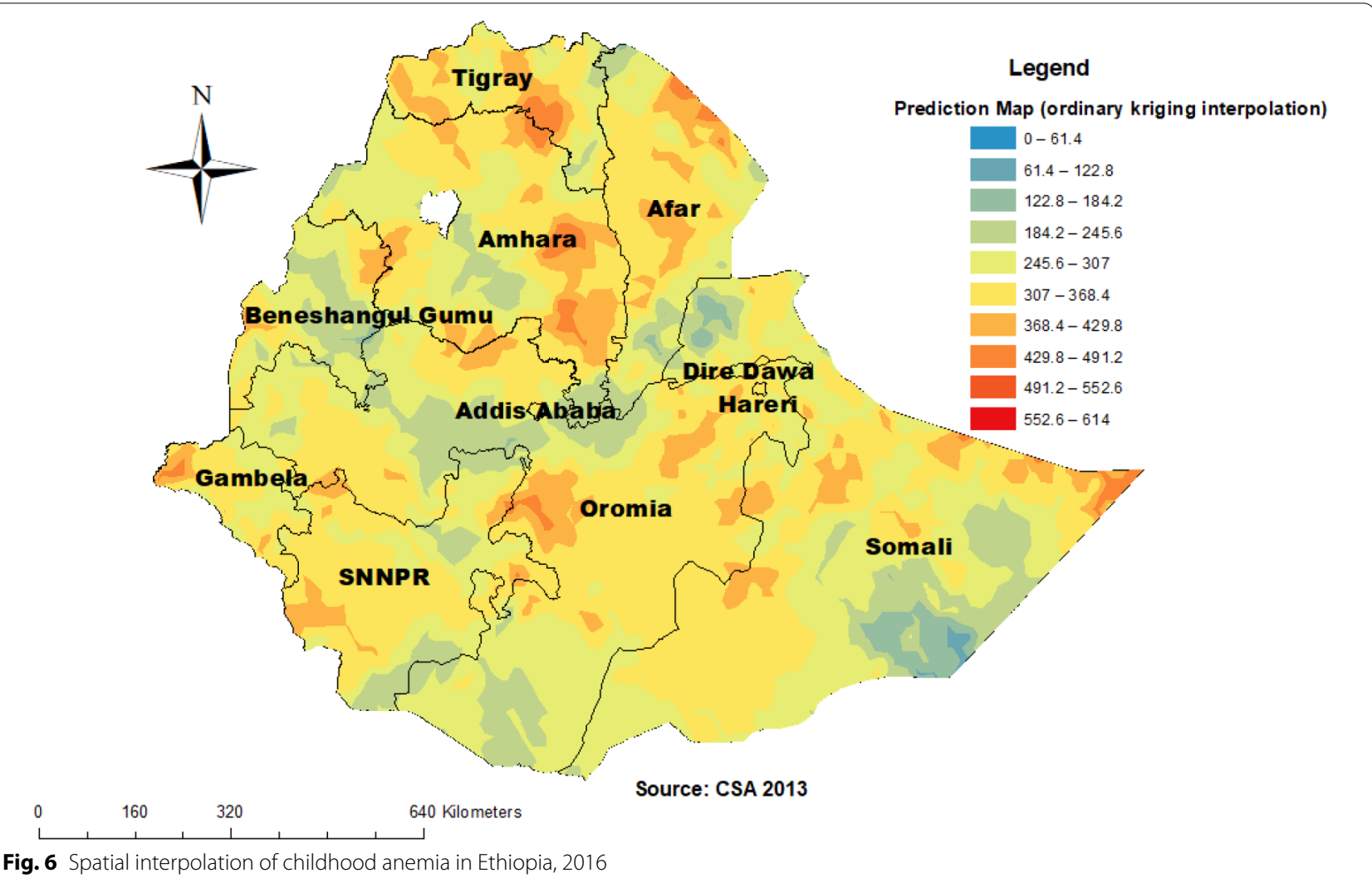




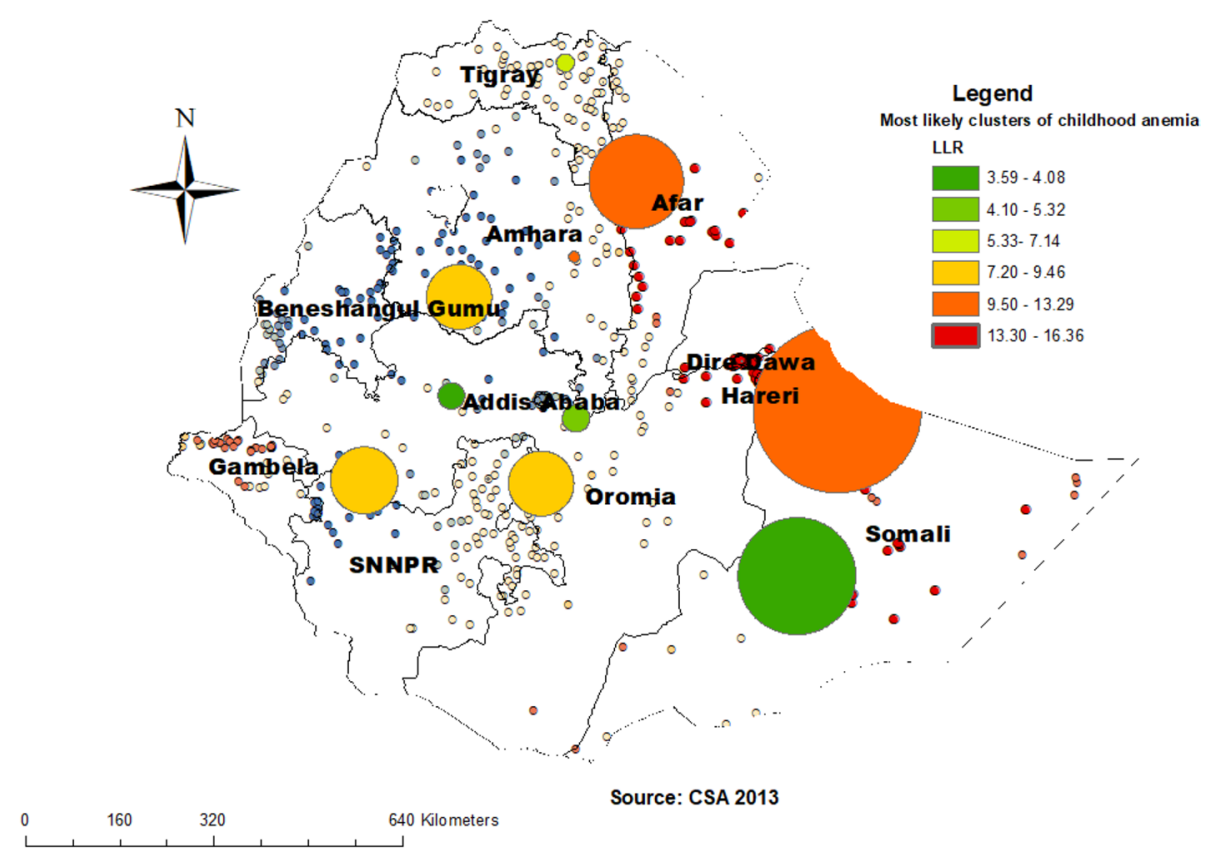

Fig. 7 Spatial SaT Scan analysis of childhood anemia in Ethiopia, 2016

and richest was lower by $25.8,40.4,35.2$, and $43.3 \%$ compared with those with family wealth index of poorest, respectively. The finding is supported by studies conducted in Brazil $[9,13]$, Nigeria [11], and Ethiopia $[10,12]$. Evidence suggested that children from lower socioeconomic status are susceptible to various nutritional disorders like anemia, as well as prone to easily preventable diseases [39-41]. That is why children from the poorest families are less likely to provide a balanced diet because no capability to afford and utilized diversified foods and they are prone to poor health conditions that cause anemia like parasitic infections [4, 42].

The odds of developing anemia in a child whose mother was currently working is lower by $13.3 \%$ as compared with those whose mother was currently not working. This finding was consistent with the previous study conducting Ethiopia [16]. The possible reason could be increased empowerment of working mothers to care for their children and other health-related actions [43, 44]. Therefore, working mothers are exposed to different health education regarding child caring and they know the impact of disease very well.

Maternal anemia is also another important factor of childhood anemia. The odds of having anemia in children whose mother was anemic is 1.53 times as compared to their counterparts. The result is in line with findings in Cuba [19], Burma [13], and Ethiopia [16]. This is the fact that maternal anemia can be a risk factor for the development of childhood anemia [45]. It is explained by the influence of poor maternal iron reserve

Table 2 Sat Scan analysis of significant clusters of childhood anemia in Ethiopia among children aged 6 to 59 months, 2016

\begin{tabular}{|c|c|c|c|c|c|c|c|}
\hline Clusters & Enumeration areas (clusters) detected & Coordinates/radius & Population & Cases & RR & LLR & $P$-value \\
\hline $1(1)$ & 301 & $(7.775278 \mathrm{~N}, 37.939392 \mathrm{E}) / 0 \mathrm{~km}$ & 32 & 32 & 1.67 & 16.36 & $<0.001$ \\
\hline $2(2)$ & 421,8 & $(11.195383 \mathrm{~N}, 39.269363 \mathrm{E}) / 9.21 \mathrm{~km}$ & 26 & 26 & 1.67 & 13.29 & $<0.001$ \\
\hline $3(41)$ & $\begin{array}{l}202,117,316,620,328,294,616,351,127,579,516,601 \\
634,573,156,5,15,290,104,268,551,613,497,85,292 \\
512,555,16,566,539,276,392,424,481,633,627,137 \\
585,317,361,480\end{array}$ & & 503 & 354 & 1.19 & 12.42 & 0.001 \\
\hline $4(1)$ & 610 & $10.102213 \mathrm{~N}, 34.826457 \mathrm{E}) / 0 \mathrm{~km}$ & 29 & 28 & 1.61 & 10.87 & 0.008 \\
\hline $5(17)$ & $\begin{array}{l}594,644,412,401,416,326,543,318,454,513,501,419 \\
186,270,281,213,619\end{array}$ & $12.349981 \mathrm{~N}, 40.242399 \mathrm{E}) / 80.40 \mathrm{~km}$ & 233 & 173 & 1.25 & 10.68 & 0.01 \\
\hline $6(8)$ & $574,499,635,82,95,11,146,625$ & $(7.708677 \mathrm{~N}, 38.758496 \mathrm{E}) / 55.60 \mathrm{~km}$ & 87 & 71 & 1.36 & 9.46 & 0.03 \\
\hline
\end{tabular}


Table 3 i-variable and multi-variable mixed-effects logistic regression analysis for determinants of anemia among children aged 6 to 59 months in Ethiopia from January 18 to June 27 in $2016(N=7794)$

\begin{tabular}{|c|c|c|c|c|}
\hline \multirow[t]{2}{*}{ Variables } & \multicolumn{2}{|c|}{ Anemic status } & \multirow[t]{2}{*}{ COR (95\%) } & \multirow[t]{2}{*}{ AOR $(95 \% \mathrm{Cl})$} \\
\hline & Non-anemic & Anemic & & \\
\hline \multicolumn{5}{|l|}{ Residency } \\
\hline urban & 608 & 719 & 1 & 1 \\
\hline rural & 2496 & 3971 & $1.47(1.20-1.80)$ & $0.89(0.68-1.17)$ \\
\hline \multicolumn{5}{|c|}{ Age of child in months } \\
\hline $6-11$ & 200 & 714 & 1 & 1 \\
\hline $12-23$ & 497 & 1268 & $0.71(0.57-0.86)$ & $0.68(0.55-0.85)^{*}$ \\
\hline $24-35$ & 646 & 1056 & $0.40(0.33-0.49)$ & $0.38(0.31-0.47)^{*}$ \\
\hline $36-47$ & 770 & 886 & $0.26(0.21-0.32)$ & $0.25(0.20-0.31)^{*}$ \\
\hline $48-59$ & 991 & 766 & $0.17(0.14-0.21)$ & $0.16(0.13-1.20)$ \\
\hline \multicolumn{5}{|c|}{ Maternal educational level } \\
\hline No education & 1903 & 3181 & 1 & 1 \\
\hline primary & 840 & 1141 & $0.90(0.79-1.02)$ & $0.95(0.82-1.11)$ \\
\hline secondary & 233 & 253 & $0.75(0.60-0.93)$ & $0.83(0.63-1.10)$ \\
\hline higher & 128 & 115 & $0.60(0.44-0.82)$ & $0.76(0.51-1.12)$ \\
\hline \multicolumn{5}{|c|}{ Religion of mother } \\
\hline orthodox & 1243 & 1107 & 1 & 1 \\
\hline Protestant & 641 & 776 & $1.24(1.02-1.49)$ & $1.213(0.99-1.48)$ \\
\hline Muslim & 1145 & 2692 & $2.48(2.11-2.91)$ & $2.07(1.75-2.46)^{* *}$ \\
\hline others & 75 & 115 & $1.71(1.17-2.49)$ & $1.49(1.01-2.22)^{*}$ \\
\hline \multicolumn{5}{|l|}{ Wealth index } \\
\hline poorest & 849 & 2005 & 1 & 1 \\
\hline poorer & 568 & 819 & $0.69(0.59-0.81)$ & $0.74(0.63-0.88)^{*}$ \\
\hline middle & 543 & 613 & $0.56(0.47-0.67)$ & $0.60(0.50-0.72)^{*}$ \\
\hline richer & 465 & 518 & $0.56(0.47-0.68)$ & $0.65(0.53-0.79)^{*}$ \\
\hline richest & 679 & 735 & $0.46(0.38-0.55)$ & $0.57(0.44-0.74)^{*}$ \\
\hline \multicolumn{5}{|c|}{ Husband's educational level } \\
\hline No education & 1317 & 2305 & 1 & 1 \\
\hline primary & 1034 & 1420 & $0.89(0.78-1.00)$ & $1.01(0.88-1.16)$ \\
\hline secondary & 304 & 404 & $0.86(0.71-1.05)$ & $1.02(0.81-1.27)$ \\
\hline higher & 220 & 294 & $0.84(0.67-1.06)$ & $1.26(0.95-1.68)$ \\
\hline \multicolumn{5}{|c|}{ Mother's current working status } \\
\hline Not working & 1317 & 3501 & 1 & 1 \\
\hline Working & 1022 & 1187 & $0.76(0.68-0.86)$ & $0.87(0.76-0.99)^{*}$ \\
\hline \multicolumn{5}{|c|}{ Maternal anemic status } \\
\hline Non-anemic & 2291 & 2708 & 1 & 1 \\
\hline Anemic & 813 & 1982 & $1.60(1.43-1.80)$ & $1.53(1.35-1.73)^{*}$ \\
\hline \multicolumn{5}{|c|}{ Size of a child at birth } \\
\hline Average & 1372 & 1943 & 1 & 1 \\
\hline Above average & 997 & 1375 & $0.95(0.84-1.07)$ & $0.97(0.85-1.10)$ \\
\hline Below average & 700 & 1338 & $1.21(1.07-1.38)$ & $1.11(0.96-1.27)$ \\
\hline \multicolumn{5}{|c|}{ Number of under-five children } \\
\hline 1-2 children & 2622 & 3655 & 1 & 1 \\
\hline$\geq 3$ children & 482 & 1035 & $1.27(1.10-1.46)$ & $1.19(1.03-1.38)^{*}$ \\
\hline \multicolumn{5}{|c|}{ Maternal age in years } \\
\hline $15-24$ & 620 & 1137 & 1 & 1 \\
\hline $25-29$ & 912 & 1443 & $0.87(0.75-1.01)$ & $1.05(0.89-1.23)$ \\
\hline $30-34$ & 714 & 1064 & $0.83(0.71-0.96)$ & $1.06(0.89-1.26)$ \\
\hline
\end{tabular}


Table 3 (continued)

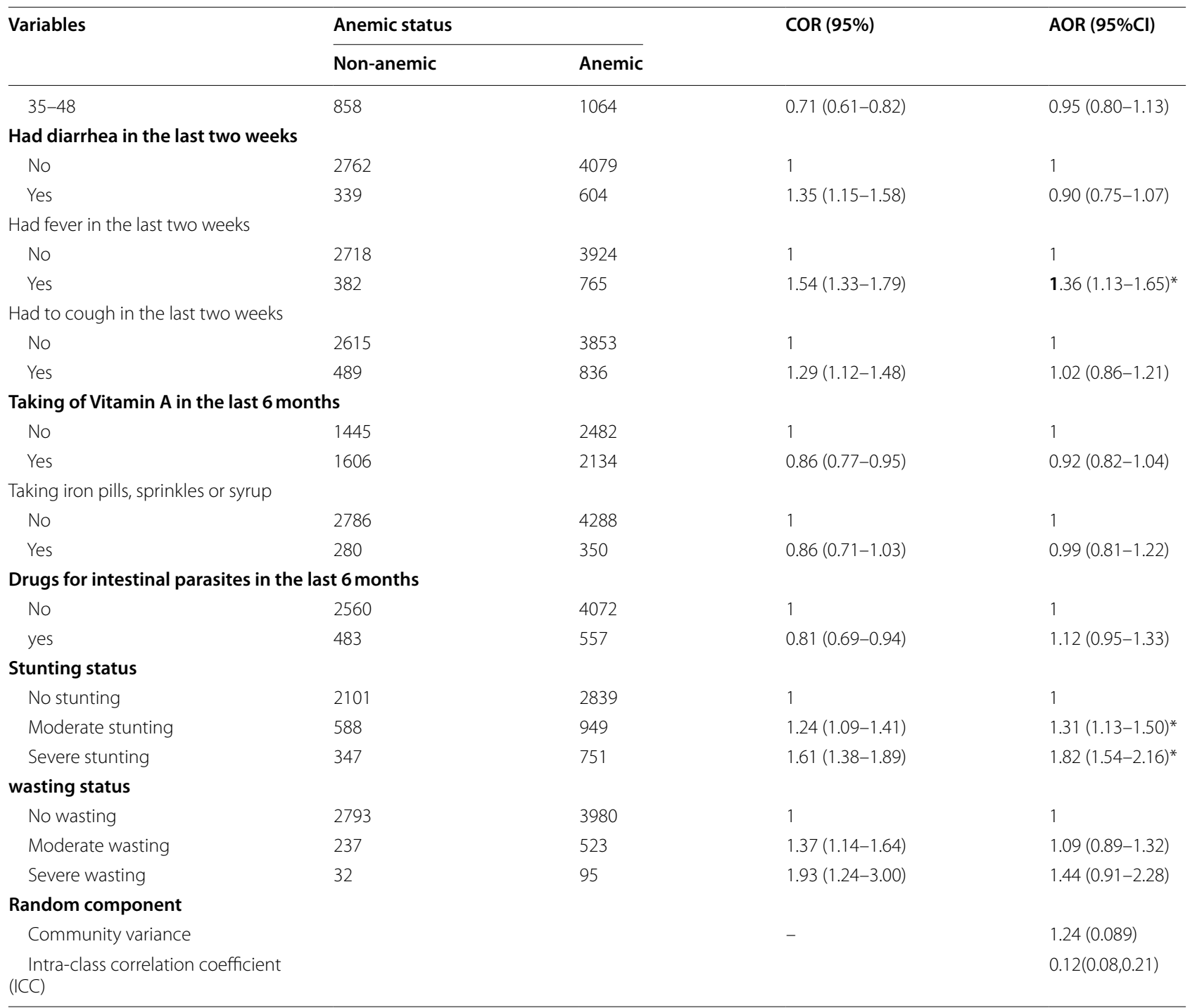

* $p$-value $<0.05$ statistically significant

during pregnancy and breastfeeding on the iron store of their child [46, 47]. Besides, maternal anemia increases the risk of maternal death, preterm birth, and low birth weight $[48,49]$. This leads to children being more prone to develop anemia.

The odds of developing anemia in children whose household had three or more under-five children is 1.19 times that of children whose household had one or two under-five children. This result was concordant with previous studies conducted in Brazil [14], Lao People's Democratic Republic [15], and Ethiopia [16]. The possible reason could be when the number of under-five children increases has an impact on health problems due to competition for foods, getting appropriate health care services this also leads to infections and cross contaminations [50]. This might worsen the quality of care for children, and increase the risk of anemia.

Fever is also one of the determinants of childhood anemia. The odds of developing anemia in children who had a fever within the last 2 weeks preceding the interview is 1.36 times that of children who had no fever within the last 2 weeks. This finding is consistent with studies conducted in Burma [13], Nigeria [11], and Southern Ethiopia [18]. This could be a fever in children that can be caused by different infectious diseases like malaria, septicemia, tuberculosis, and kalazar that cause anemia by infecting and destructing red blood cells or by different mechanisms [51]. 
Children with moderate or severe stunting were 1.30 and 1.82 times more likely to have anemia than children who were not stunted. This result is in agreement with previous studies conducted in Burma [13], Kenya [20], and Ethiopia [10, 12, 16-18, 24]. Pathophysiological explanation implies reverse causation between stunting and anemia. In malnourished children, gastrointestinal epithelium disturbance leads to the development of anemia by impairing the absorption of nutrients [51]. on the other hand, anemia during the period of rapid growth leads to irreversible growth retardation $[4,46]$, coexist with other micronutrient deficiencies, and stunting may increase the development of anemia by a synergism association. The problem of anemia continues to be a public health challenge in these countries, particularly in Africa, with serious consequences for the most vulnerable populations such as children and pregnant women. Therefore, to reduce childhood anemia in different settings policies and programs for anemia control should account for the spatial heterogeneity of anemia.

\section{Strength and limitations of the study}

The strengths of this study, first, the study was based on nationally representative weighted data and can be generalized at the national level. Second, the use of spatial analysis to explore the spatial variation and significant hotspot areas of childhood anemia and using the mixed-effect advanced model to get a real estimate. The limitation of this study is some variables there is retrospective nature so mothers were asked to remember events that happen in the past which leads to recall bias and it is secondary data collected at appoint in time so doesn't show temporal relationship.

\section{Conclusion}

This study found that childhood anemia was not random in Ethiopia. High-risk areas for childhood anemia were found in West of part Oromia, Harari, Dire Dawa, North West Somali, and entire and North West Afar regions of the country. Anemia is a major public health problem in Ethiopia in under-five children. In general, age of child, wealth index, mother's current working status, maternal anemic status, number of under-five children in the household, fever in the last 2 weeks, and stunting were variables that had achieved statically significant association for childhood anemia. Therefore, high-risk areas for childhood anemia needs to be given priority and targeted with interventions to reduce the burden of childhood anemia in under-five children.

\section{Abbreviations}

AIC: Akaikie Information Critreia; AOR: Adjusted Odds Ratio; BIC: Bayesian Information Criteria; COR: Crude Odds Ratio; EDHS: Ethiopian Demographic and Health Survey; ICC: Intra Class Correlation; LLR: Log Likelihood Ratio test.
Acknowledgments

We would like to acknowledge the Ethiopian demographic and health survey staff and major DHS programs for permitting data access.

\section{Authors' contributions}

Data curation, formal analysis, resources, software, validation, visualization: Tiruneh Ayele, Destaw Fetene Teshome, Lemma Derseh Gezie, Chilot Desta Agegnehu,

The investigation, Methodology, supervision, conceptualization, analysis, and interpretation writing a detailed review, editing, and preparing manuscript: Tiruneh Ayele, Destaw Fetene Teshome, Lemma Derseh Gezie, Chilot Desta Agegnehu. Finally all the authors approved the final manuscript.

\section{Funding}

The authors received no specific funding for this work.

\section{Availability of data and materials}

All relevant data are publically available and here is the link to the Ethiopian Demographic and Health Survey 2016 data and you can access the data by clicking the following link https://dhsprogram.com/data/dataset/Ethiopia_ Standard-DHS_2016.cfm?flag $=0$

\section{Declarations}

\section{Ethics approval and consent to participate}

Our study was based on secondary data from Ethiopian Demographic and Health survey and we have secured the permission letter from major Demographic Health and Survey.

Written consent was obtained from the Measure DHS International Program which authorized the data sets. Permission for data access was obtained from major demographic and health surveys through the online request form http://www.dhsprogram.com. All the data used in this study are publicly available, aggregated secondary data with not having any personal identifying information that can be linked to particular individuals, communities, or study participants.

\section{Consent for publication}

It is not applicable.

\section{Competing interests}

All authors declare that they have no competing interest final content of the manuscript.

\section{Author details}

${ }^{1}$ Department of Epidemiology and Biostatistics, Institute of Public Health, College of Medicine and Health Sciences, University of Gondar, Gondar, Ethiopia. ${ }^{2}$ School of Nursing, College of Medicine and Health Sciences and Comprehensive specialized hospital, University of Gondar, Gondar, Ethiopia.

Received: 22 May 2021 Accepted: 23 August 2021

Published online: 09 November 2021

\section{References}

1. WHO V. Haemoglobin concentrations for the diagnosis of anaemia and assessment of severity. Geneva: Vitamin and Mineral Nutrition Information System, WHO; 2011.

2. Organization $\mathbf{W H}$. Assessing the iron status of populations: report of a joint World Health Organization/Centers for Disease Control and Prevention technical consultation on the assessment of iron status at the population level. Geneva: World Health Organization; 2007.

3. Kassebaum NJ, Collaborators GA. The global burden of anemia. Hematol Oncol Clin North Am. 2016;30(2):247-308.

4. Benoist Bd, McLean E, Egll I, Cogswell M. Worldwide prevalence of anaemia 1993-2005: WHO global database on anaemia. 2008. p. 4-7.

5. Organization WH. Global Health Observatory data repository: prevalence of anaemia in women Accessed 2 May 2018 http://apps.who.int/gho/ data/viewmainGSWCAH28REG; 2016. 
6. Agency C. Ethiopia Demographic and Health Survey Addis Ababa. USA: Ethiopia ICF International Calverton; 2011.

7. Agency CS. Ethiopian demographic and health survey 2016. Addis Ababa, Ethiopia, and Rockville, Maryland, USA CSA and ICF: Key Indicators Report; 2016.

8. Magalhães RJS, Clements AC. Spatial heterogeneity of haemoglobin concentration in preschool-age children in sub-Saharan Africa. Bull World Health Organ. 2011;89(6):459-68.

9. Cardoso MA, Scopel KK, Muniz PT, Villamor E, Ferreira MU. Underlying factors associated with anemia in Amazonian children: a population-based, cross-sectional study. PLoS One. 2012;7(5):e36341.

10. Gari T, Loha E, Deressa W, Solomon T, Atsbeha H, Assegid M, et al. Anaemia among children in a drought affected community in south-Central Ethiopia. PLoS One. 2017;12(3):e0170898.

11. Gayawan E, Arogundade ED, Adebayo SB. Possible determinants and spatial patterns of anaemia among young children in Nigeria: a Bayesian semi-parametric modelling. Int Health. 2014;6(1):35-45.

12. Woldie H, Kebede $\mathrm{Y}$, Tariku A. Factors associated with anemia among children aged 6-23 months attending growth monitoring at Tsitsika health center, wag-Himra zone, Northeast Ethiopia. J Nutr Metab. 2015;2015:928632.

13. Zhao A, Zhang Y, Peng Y, Li J, Yang T, Liu Z, et al. Prevalence of anemia and its risk factors among children 6-36 months old in Burma. Am J Trop Med Hyg. 2012;87(2):306-11.

14. Gondim SSR, Diniz AS, RAd S, RGdS B, ECd A, AdA P. Magnitude, time trends and factors associate with anemia in children in the state of Paraíba, Brazil. Rev Saude Pub. 2012;46(4):649-56.

15. Kounnavong S, Sunahara T, Hashizume M, Okumura J, Moji K, Boupha $B$, et al. Anemia and related factors in preschool children in the southern rural Lao People's Democratic Republic. Trop Med Health. 2011;39(4):95-103.

16. Muchie KF. Determinants of severity levels of anemia among children aged 6-59 months in Ethiopia: further analysis of the 2011 Ethiopian demographic and health survey. BMC Nutrition. 2016;2(1):51.

17. Gebreegziabiher G, Etana B, Niggusie D. Determinants of anemia among children aged 6-59 months living in Kilte Awulaelo Woreda, Northern Ethiopia. Hindawi J Anemia. 2014:1-6.

18. Tiku YS, Mekonnen TC, Workie SB, Amare E. Does Anaemia have major public health importance in children aged 6-59 months in the Duggina Fanigo District of Wolaita zone, southern Ethiopia? Ann Nutr Metab. 2018;72(1):3-11.

19. Pita GM, Jiménez S, Basabe B, García RG, Macías C, Selva L, et al. Anemia in children under five years old in eastern Cuba, 2005-2011. Medicc Rev. 2014;16(1):16-23.

20. Foote EM, Sullivan KM, Ruth LJ, Oremo J, Sadumah I, Williams TN, et al. Determinants of anemia among preschool children in rural, western Kenya. Am J Trop Med Hyg. 2013;88(4):757-64.

21. Semedo RM, Santos MM, Baião MR, Luiz RR, da Veiga GV. Prevalence of anaemia and associated factors among children below five years of age in Cape Verde, West Africa. J Health Popul Nutr. 2014;32(4):646.

22. Dey S, Goswami S, Dey T. Identifying predictors of childhood anaemia in North-East India. J Health Popul Nutr. 2013;31(4):462.

23. Konstantyner T, Roma Oliveira TC, de Aguiar Carrazedo Taddei JA. Risk factors for anemia among Brazilian infants from the 2006 National Demographic Health Survey. Anemia. 2012;2012.

24. Roba KT, O'Connor TP, Belachew T, O'Brien NM. Anemia and undernutrition among children aged 6-23 months in two agroecological zones of rural Ethiopia. Pediatric Health Med Ther. 2016;7:131.

25. Tengco LW, Rayco-Solon P, Solon JA, Sarol JN Jr, Solon FS. Determinants of anemia among preschool children in the Philippines. J Am Coll Nutr. 2008;27(2):229-43.

26. Ababa A, Calverton E. Central statistical agency (Ethiopia) and ICF international. Ethiopia Demographic and Health Survey: Ethiopia and Calverton; 2011.

27. Rodriguez G, Elo I. Intra-class correlation in random-effects models for binary data. Stata J. 2003:3(1):32-46.

28. Zulu LC, Kalipeni E, Johannes E. Analyzing spatial clustering and the spatiotemporal nature and trends of HIV/AIDS prevalence using GIS: the case of Malawi, 1994-2010. BMC Infect Dis. 2014;14(1):285.
29. Anselin L, Sridharan S, Gholston S. Using exploratory spatial data analysis to leverage social indicator databases: the discovery of interesting patterns. Soc Indic Res. 2007;82(2):287-309.

30. Krivoruchko K. Empirical bayesian kriging. ArcUser Fall. 2012:6-10.

31. Naish S, Tong S. Hot spot detection and spatio-temporal dynamics of dengue in Queensland, Australia. Int Arch Photogrammetry Remote Sensing Spatial Inf Sci. 2014;40(8):197.

32. Bhunia GS, Shit PK, Maiti R. Comparison of GIS-based interpolation methods for spatial distribution of soil organic carbon (SOC). J Saudi Soc Agric Sci. 2018;17(2):114-26.

33. Woldemichael A, Takian A, Sari AA, Olyaeemanesh A. Inequalities in healthcare resources and outcomes threatening sustainable health development in Ethiopia: panel data analysis. BMJ Open. 2019;9(1):e022923.

34. Disha A, Tharaney M, Abebe Y, Alayon S, Winnard K. Factors associated with infant and young child feeding practices in Amhara region and nationally in Ethiopia: analysis of Ethiopia demographic and health surveys 2005 and 2011; 2015.

35. Black MM, Quigg AM, Hurley KM, Pepper MR. Iron deficiency and irondeficiency anemia in the first two years of life: strategies to prevent loss of developmental potential. Nutr Rev. 2011;69(s1).

36. Weatherhead JE, Hotez PJ. Worm Infections in Children. Pediatr Rev. 2015;36(8):341-52.

37. Organization WH. Deworming in children 2017.

38. Moschovis PP, Wiens MO, Arlington L, Antsygina O, Hayden D, Dzik W, et al. Individual, maternal and household risk factors for anaemia among young children in sub-Saharan Africa. BMJ Open. 2018;8(5):1-2.

39. Khan JR, Awan N, Misu F. Determinants of anemia among 6-59 months aged children in Bangladesh: evidence from nationally representative data. BMC Pediatr. 2016;16(1):1-12.

40. Moschovis PP, Wiens MO, Arlington L, Antsygina O, Hayden D, Dzik W, et al. Individual, maternal and household risk factors for anaemia among young children in sub-Saharan Africa: a cross-sectional study. BMJ Open. 2018;8(5):e019654.

41. Habyarimana F, Zewotir T, Ramroop S. Structured additive quantile regression for assessing the determinants of childhood anemia in Rwanda. Int J Environ Res Public Health. 2017;14(6):652.

42. Allen L, Dary O, de Benoist B, Hurrel R. WHO guidelines on food fortification with micronutrients; WHO: Geneva, Switzerland, 2006; 2010.

43. Datta PB, Gailey R. Empowering women through social entrepreneurship: case study of a women's cooperative in India. Entrepreneurship Theory aPract. 2012;36(3):569-87.

44. Presser H, Sen G. Women's empowerment and demographic processes: moving beyond Cairo: Oxford University press; 2000.

45. Shukla AK, Srivastava S, Verma G. Effect of maternal anemia on the status of iron stores in infants: a cohort study. J Fam Community Med. 2019;26(2):118.

46. Kotecha PV. Nutritional anemia in young children with focus on Asia and India. Indian J Commun Med. 2011;36(1):8.

47. Pasricha S-R, Black J, Muthayya S, Shet A, Bhat V, Nagaraj S, et al. Determinants of anemia among young children in rural India. Pediatrics. 2010;126(1):e140-e9.

48. Menon KC, Ferguson EL, Thomson CD, Gray AR, Zodpey S, Saraf A, et al. Effects of anemia at different stages of gestation on infant outcomes. Nutrition. 2016:32(1):61-5.

49. Allen LH. Anemia and iron deficiency: effects on pregnancy outcome. Am J Clin Nutr. 2000;71(5):1280S-4S.

50. Feleke BE. Nutritional status and intestinal parasite in school age children: a comparative cross-sectional study. Int J Pediatr. 2016;2016.

51. Organization WH. Pocket book of hospital care for children: guidelines for the management of common childhood illnesses: World Health Organization; 2013.

\section{Publisher's Note}

Springer Nature remains neutral with regard to jurisdictional claims in published maps and institutional affiliations. 